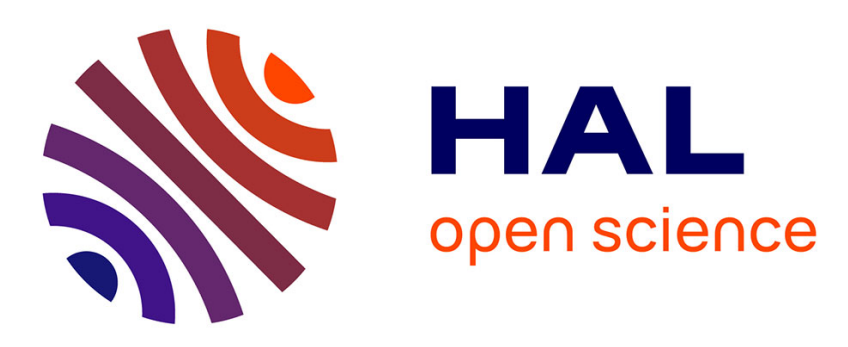

\title{
The four stages of the knowledge sharing process in SMEs
}

\author{
Amitabh Anand, Isabelle Walsh
}

\section{To cite this version:}

Amitabh Anand, Isabelle Walsh. The four stages of the knowledge sharing process in SMEs. International Journal of Entrepreneurship and Innovation Management, 2020, 24 (6), pp.465-481. 10.1504/IJEIM.2020.110100 . halshs-03053361

\section{HAL Id: halshs-03053361 https://shs.hal.science/halshs-03053361}

Submitted on 11 Dec 2020

HAL is a multi-disciplinary open access archive for the deposit and dissemination of scientific research documents, whether they are published or not. The documents may come from teaching and research institutions in France or abroad, or from public or private research centers.
L'archive ouverte pluridisciplinaire HAL, est destinée au dépôt et à la diffusion de documents scientifiques de niveau recherche, publiés ou non, émanant des établissements d'enseignement et de recherche français ou étrangers, des laboratoires publics ou privés. 


\title{
The four stages of the knowledge sharing process in SMEs
}

\section{Amitabh Anand* and Isabelle Walsh}

SKEMA Business School, Université Côte d'Azur, GREDEG, France

Email: amitabh.anand@skema.edu

Email: isabelle.walsh@skema.edu

*Corresponding author

\begin{abstract}
This paper takes an exploratory and qualitative stance to investigate and understand how employees within SMEs share their knowledge in a dyadic situation. The research is set in an Indian context. Through participant observation and interviews with both supervisors and employees, we unmask the four essential stages of the dyadic process through which knowledge sharing occurs: identification, medium selection, engagement, and feedback. Based on our findings, we highlight theoretical and practical implications for SME business leaders.
\end{abstract}

Keywords: knowledge sharing; knowledge sharing process; dyadic relation; SMEs; India.

Reference to this paper should be made as follows: Anand, A. and Walsh, I. (xxxx) 'The four stages of the knowledge sharing process in SMEs', Int. J. Entrepreneurship and Innovation Management, Vol. X, No. Y, pp.xxx-xxx.

Biographical notes: Amitabh Anand is an Assistant Professor at SKEMA Business School, Universite Cote d'Azur, France. His research focuses primarily on knowledge management, SMEs and virtues. He has won several scholarship and awards for his research was given the Excellence in Peer Review Award from South Asian Journal of Human Resources Management for the year 2018; Emerging Scholar Award from organisation studies research network in Germany in 2018, KM and IC Excellence Award nomination for a best-case study on ShaRP in Padova, Italy. He serves as a reviewer for the European Academy of Management and the British Academy of Management. His works have been published at Journal of Knowledge Management, Journal of Knowledge Economy, etc.

Isabelle Walsh is a Distinguished Professor at SKEMA Business School, Universite Côte d'Azur, France. She is actively involved in the development of methodological design and bibliometric research (which include grounded theory with mixed quantitative and qualitative data), and her research interests are the use of information systems, mindfulness, strategic alignment, quality in higher education, sharing of knowledge and problems of cultural management and change. Her research has been published in world-renowned journals (European Journal of Information Systems, Journal of Strategic Information Systems, Mechanism, Organizational Research Methods, Information Systems \& Management, etc.). Beyond her academic activities, she has extensive experience in business and consulting.

Copyright (C) 20XX Inderscience Enterprises Ltd. 
This paper is a revised and expanded version of a paper entitled 'The different stages of knowledge sharing process in SMEs' presented at Association Information and Management (AIM) in Paris, France, 17-19 May 2017.

\section{Introduction}

Knowledge sharing (KS) has always been a critical issue for small and medium-sized enterprises (SMEs) (Egbu et al., 2005). However, the process of KS in SMEs remains understudied. The literature has mostly focused on large firms, and there is no detailed model which describes the mechanism of KS in SMEs at the individual level from a dyadic perspective i.e., between knowledge seeker and the provider. The scarce amount of empirical evidence of KS in SMEs that is found in the literature arises mostly from Western, Chinese and European contexts. This paper attempts to investigate and understand the KS process between employees in SMEs in an Indian context.

Knowledge is an asset that helps organisations develop competitive advantage (Ipe, 2003). Individuals working in organisations are an important source of knowledge, and organisations are reliant on the knowledge that is shared among employees to reap possible benefits and become innovative and competitive, (Brčić and Mihelic, 2015). An organisation's ability to grow is greatly impeded if employees do not share their personal (tacit) knowledge (Cabrera and Cabrera, 2002). However, sharing knowledge requires effort, resources, and time (Szulanski, 2000); an investment that not all employees are willing to make.

KS within an organisation will not be achieved if there is a lack of KS culture, trust and motivation (Wang and Noe, 2010). In practice, KS cannot be forced but can only be encouraged and facilitated (Gibbert and Krause, 2002; Bock et al., 2005). Attempts have been made to examine the conditions under which employees may or may not share their knowledge in firms (e.g., Wang and Noe, 2010; Srivastava et al., 2006; Bartol and Srivastava, 2002). However, the understanding of how individuals actually share knowledge and the process of KS itself remain both poorly understood (Andolsek, 2011), and largely understudied in the context of SMEs (Reige, 2005; Massaro et al., 2016).

In large organisations, the process of KS focuses on people, systems and technology, whereas in SMEs, with their limited number of employees, the focus is more on people and social relationships (Andolsek, 2011). The sharing of knowledge in SMEs occurs via people mechanisms (Desouza and Awazu, 2006), and the nature of the knowledge shared is mostly tacit (Cohen and Kaimnekais, 2007).

Investigation into the factors that shape and influence KS behaviours in organisations is ongoing (Ibrahim and Heng, 2015) and these factors have not yet been systematically explored (Eze et al., 2013). The process of KS within different geographical contexts also remains unexplored (Anand and Walsh, 2015) and very few studies have been conducted in an Indian context and those that have are limited to engineering and automotive industries (Singh et al., 2006; Pillania, 2008). Furthermore, very few studies about KS in SMEs have concentrated on the antecedents of the KS process (enablers and barriers) and thus provide little insight into the complex process of KS itself.

In the present article we address these gaps and model the KS process at the individual level, from a dyadic (seeker and provider) perspective. For context setting, we 
adopt the definition of KS proposed by Paulin and Suneson, (2012, p.83): "An exchange of knowledge between two individuals: one who communicates knowledge and one who assimilates it". We focus specifically on the individual and interpersonal perspectives, while taking into consideration the organisational environment.

The article is organised as follows. We first survey the literature about the KS process and detail our research methodology. We then present and discuss our findings before concluding and highlighting the theoretical and practical implications of our study.

\section{Literature review}

In this section, we survey the literature about theKS process in general, and more specifically in SMEs in the context of our research which is set in India. We highlight some theoretical gaps and the lack of any holistic perspective on the KS process itself.

\subsection{Understanding the KS process}

The KS process refers to the nature of knowing, the various stages through which knowledge is shared from one party to another, how it is shared and the means adopted to ease the flow of knowledge during this process (Tabrizi and Morgan, 2014). The process involves actively communicating what one knows to others (Van den Hooff and de Ridder, 2004). The KS process involves at least two parties and occurs mostly through dyadic relationships (Fernie et al., 2003). It relies on the cooperative relationships between different members of an organisation and on the behaviour they adopt during the sharing process (Zhang and Jiang, 2015). Knowledge is highly individualistic, embedded in specific social, cognitive, and behavioural contexts, and dyadic cohesiveness becomes a crucial element in the KS process (Michailova and Hutchings, 2004). In this perspective, Zhang and Jiang (2015) proposed that in a dyadic responsive KS interaction, the personal relationship between the seeker and provider is key for the sharing process to be effective. Further, in this dyadic process, the nature of social ties between the seeker and provider is also important. Such ties depend on the frequency of interaction, the communication and collaboration between the seeker and provider and the closeness of their relationship (Naif-Marouf, 2007). In other words, the closer the employees, the higher the probability that the process of KS will unfold. Social ties also depend on culture, regional and country particularities. KS can also occur due to various circumstances, e.g., according to Liang et al. (2008) individuals share knowledge for two reasons, first to gain certain benefits for future or social exchange and second, to improve their perceived self-efficacy.

However, KS also depends on the willingness and eagerness of individuals to share with others (Ismail et al., 2009). In order for knowledge to be effective within an organisation, workers have to establish a deep connection to better understand the knowledge-giver's thoughts (Brčić and Mihelic, 2015). KS can develop either through direct physical interaction among people or through indirect interaction, for instance via document creation. The central role of face-to-face conversations in the KS process is evident (Alavi and Leidner, 2001), as KS requires dynamic interaction (Shariq, 1999) and good relationships between employees (Brčić and Mihelic, 2015). 
There is a lack of consensus in the literature about KS mechanisms, with different and sometimes contrasting disciplines being suggested and investigated. These differences have not been acknowledged, nor have the suggested mechanisms been systematically compared (Berends, 2005). A large part of the literature assumes that KS is initiated by an individual searching for a specific piece of knowledge that they retrieve from someone else who possesses this knowledge. Others, for example Davenport and Prusak (1998), Lin (2005), and Hansen (1999) suggest a two-stage model of the KS mechanism in which the knowledge source (provider) first collects the necessary knowledge elements and sends the required knowledge to the knowledge receiver (seeker). Another example that helps understand the KS process is found in the works of Szulanski (1996). He proposed a four-stage model: initiation, implementation, ramp-up, and integration. This model is based on the rich empirical research on technology transfer, social change, innovation diffusion, and implementation. It was applied and extended by Tabrizi and Morgan (2014) in the healthcare industry through a conceptual model involving the four stages of the KS process: initiation, requirements, implementation and follow up.

\subsection{KS in SMEs}

SME management has many particularities. For instance, in small companies, due to the limited number of employees and managers, many functions are accumulated within the competence of only a few workers; informal leadership is more common, and oral communication is preferred (Egbu et al., 2005; Anand and Walsh, 2015). SMEs act as social institutions due to their nature, size, operation and unified culture, and personal relations among co-workers, bosses and subordinates become an integral part of the culture. However, awareness of KS in SMEs is still in the infancy stage (Ngah and Jusoff, 2009).

As SMEs excel at internal networking and efficient communication, KS is widespread (Desouza and Awazu, 2006). Individuals who set up SMEs do so because they have knowledge in key areas of competencies and think they can compete using such knowledge (Desouza and Awazu, 2006). Informal face-to-face social interaction is the most effective technique used to share knowledge in SMEs. Indeed, Egbu et al. (2005) highlight that knowledge shared in SMEs is tacit in nature and is essential since SMEs have scarce resources. KS is prevalent through brainstorming that produces rich tacit knowledge (Ngah and Jusoff, 2009); KS also helps SMEs to differentiate themselves from their competitors particularly in terms of resources, which should ideally be valuable, rare, limited and non-imitable (Barney, 1991). In this regard, SMEs are often faced with the challenge of facilitating KS activity while retaining a skilled workforce.

However, several studies have recognised that the KS process is complex. In some instances, employees tend to lose interest in the process of sharing their tacit knowledge thus endangering the organisation's progress and success. Consequently, many studies have attempted to understand KS practices in SMEs from different perspectives. Most of these contributions investigate KS in large firms and in terms of behaviour, attitude, intention, willingness, barriers and enablers (Bock et al., 2005; Anitha, 2006; Zhang and Jiang, 2015). However, to our knowledge, no work has yet investigated the KS process within SMEs. In this paper, we only consider the dyadic dimension (seeker and provider) of the KS process in SMEs. 


\subsection{Indian SMEs}

SMEs in India include micro, small and medium-sized enterprises (MSME) (see Appendix for classification). MSMEs constitute an important part of the Indian economy, consisting of 36 million units providing employment to over 80 million people and contributing about $8 \%$ to the national GDP, $45 \%$ to the total manufacturing output and $40 \%$ to exports (Dhamija and Arora, 2017).

According to KPMG (2015), some of the key metrics used globally to define MSMEs are annual turnover, headcount and potential export revenues. However, in India, the metric traditionally used to define the SME sectoris investment in plant and machinery because investment in assets can be objectively verified and measured. Indian SMEs have been broadly classified into two categories,

1 the production of goods pertaining to any industry

2 enterprises engaged in providing services.

In the present article, we investigated both manufacturing and service industries.

SMEs are very important to the world economy and sharing knowledge can be considered as critical to their survival. Although SMEs in India contribute greatly to a fast growing economy, they continue to struggle on multiple accounts such as inadequate scale of operations, use of obsolete technology, supply chain inefficiencies due to poor infrastructure support, increased competition in price from the products of global industries, higher loan repayments and fluctuating interest rates, inadequate planning for implementing changes in manufacturing strategies and lack of understanding of market scenarios (Jain and Gandhi, 2016). These companies must share knowledge internally, as well as externally, as they aim to improve their viability and, if possible, to grow in uncertain times (Dhamija and Arora, 2017).

\subsection{Theoretical gaps}

SMEs have a poor understanding of the factors that help and promote KS in organisations (Anitha, 2006). Although they are often identified and recognised as knowledge generators, they are unfortunately often poor at leveraging and exploiting their knowledge resources (Levy et al., 2003). Many of the empirical studies on KS have focused more on knowledge management in large organisations. Very few studies have contributed to KS practice in SMEs (Fink and Ploder, 2009; Anitha, 2006). Furthermore, SMEs' awareness of KS approaches is still in its infancy and is relatively embryonic in terms of management application (Ali and Murali, 2009). A common problem in introducing $\mathrm{KS}$ in SMEs is the lack of clarity about which types or methods should be considered (Fink and Ploder, 2009). The nature of knowledge in SMEs is mostly tacit (Cohen and Kaimnekais, 2007). Nonaka and Takeuchi (1995) suggest that although the flow from tacit to explicit knowledge would be beneficial for the organisation, tacit knowledge is particularly difficult to render explicit in SMEs (Wong and Radcliffe, 2000). Sharing this tacit knowledge helps to improve SMEs' performance, and is particularly effective when tacit KS takes place during socialisation and informally where SMEs have an efficient and informal communication network (Egbu et al., 2005).

SMEs have different structures and develop different patterns of behaviour, especially in adapting to the environment (Hashim, 2007). These differences vary from industry to 
industry and from country to country. For example, compared to larger firms, SMEs usually feature higher socialisation characteristics where employees work in close proximity (Cohen and Kaimnekais, 2007). The key issues related to KS corroborated by findings in the SME literature focus mostly on the human factors that affect the KS process, for example, personal motivation, the opportunity to learn, source reliability, resistance and the absorptive capacity and receptiveness of the receiver (Massaro et al., 2016). SME research reflects fragmented insights about knowledge management in SMEs and calls for deeper, more realistic insights that take into consideration the environment and working dynamics of SMEs, focusing on knowledge identification, utilisation and storage (Durst and Edvardsson, 2012). More specifically, very few studies investigate KS practices among Indian SMEs (Anand and Walsh, 2015). To integrate and extend existing views on KS in the context of Indian SMEs, we undertook an exploratory study with qualitative interviews in nine SMEs of the Bangalore region of India.

\section{Methodology}

India is a country contextualised by superficial beliefs, emotional and cultural values, and a unusual relationships resulting from these (Anand and Walsh, 2015). Given such a context, we decided to research these cognitive and emotional dimensions through in-depth interviews. Qualitative studies help gain insights into people's feelings and thoughts (Sutton and Austin, 2015). As we proceeded with data collection, we adopted an exploratory stance and some of the grounded theory precepts (Glaser et al., 1968) to identify different patterns underlying the KS behaviours between seeker and provider.

The SMEs were selected based on their accessibility and willingness to participate in interviews i.e., convenience sampling (Wrenn et al., 2007) that is acceptable for exploratory research (Glaser et al., 1968). Nine SMEs were selected based on the definition of MSMEs (see previous section), all from Bangalore city, in the southern region of India. 27 participants (three from each SMEs) were first chosen based on the recommendation from the SME owners/heads. However, we then proceeded to choose participants based on our perception that they might have interesting elements to bring to our research (theoretical sampling: Glaser et al., 1968) and on their interest in participating in our discussions.

We conducted interviews in vernacular language so that our questions made better sense to interviewees. The following questions were asked, changed and rephrased during the flow of discussion.

1 'What do you do when you need knowledge to solve a problem or to work upon something?' or 'How do you find the knowledge necessary for your work?'

2 'Where do you find the knowledge that you need for your work?' or 'Is it easy to obtain knowledge from where you think you can find it?'

3 'How does sharing knowledge happen between you and your colleagues/supervisor or others?' and 'Are there any steps involved?' or 'How is knowledge exchanged or transferred from the provider?' 
Our interviews lasted approximately 30 to 45 minutes and were conducted informally. All the respondents participated voluntarily and were assured of confidentiality and anonymity. The details of interviewees and firms are summarised in Table 1. Firms names have been coded for anonymity.

Table 1 Firms and participants

\begin{tabular}{|c|c|c|c|}
\hline Firm's & Industry & Category & Interviewees \\
\hline KOP-1 & Manufacturing & Medium & $\begin{array}{c}\text { Operation assistant, assistant supervisor and } \\
\text { delivery officer }\end{array}$ \\
\hline PEI-2 & Manufacturing & Medium & $\begin{array}{l}\text { Electrification assistant, transformer } \\
\text { operator, engineer trainee }\end{array}$ \\
\hline IIS-3 & $\begin{array}{l}\text { Market research } \\
\text { services }\end{array}$ & Small & $\begin{array}{c}\text { Data analyst, operating officer, office } \\
\text { manager }\end{array}$ \\
\hline OFS-4 & ICT services & Medium & $\begin{array}{l}\text { Admin assistant, application developer, } \\
\text { service engineer }\end{array}$ \\
\hline TE-5 & Property services & Small & $\begin{array}{c}\text { Estate assistant, office assistant, assistant } \\
\text { supervisor }\end{array}$ \\
\hline NE-6 & $\begin{array}{l}\text { Manufacturing and } \\
\text { construction }\end{array}$ & Small & $\begin{array}{l}\text { Property manager, estate assistant, office } \\
\text { establishment executive }\end{array}$ \\
\hline RE-7 & $\begin{array}{l}\text { Food exports and } \\
\text { manufacturing }\end{array}$ & Medium & $\begin{array}{c}\text { Purchase assistant, customer executive and } \\
\text { loading officer }\end{array}$ \\
\hline QCH-8 & $\begin{array}{l}\text { Food and leisure } \\
\text { services }\end{array}$ & Small & $\begin{array}{l}\text { Assistant manager, customer supervisor and } \\
\text { club officer }\end{array}$ \\
\hline A4E-9 & ICT services & Medium & $\begin{array}{l}\text { Marketing executive, customer relation } \\
\text { executive and office supervisor }\end{array}$ \\
\hline
\end{tabular}

Open coding, selective coding and theoretical coding were applied (Glaser, 1978). Open coding was first applied to the data until categories emerged. Once the core category emerged (KS process) we then selectively and theoretically coded our data towards identifying the various emerging stages of the KS process. Thus, we coded the collected data around the KS process and the various stages that emerged. We then interviewed the SMEs' CEOs and middle management to compare our data for triangulation purposes, consistency and for any information that we might have overlooked. Some illustrations of our coding are provided in the next section.

\section{Findings: a dyadic process model of KS in Indian SMEs}

In this section we summarise our findings and the model that emerged from our data (Figure 1). We found that the KS process is divided into four main stages: identification, medium selection, engagement and feedback. 
Figure 1 The KS process between seeker and provider

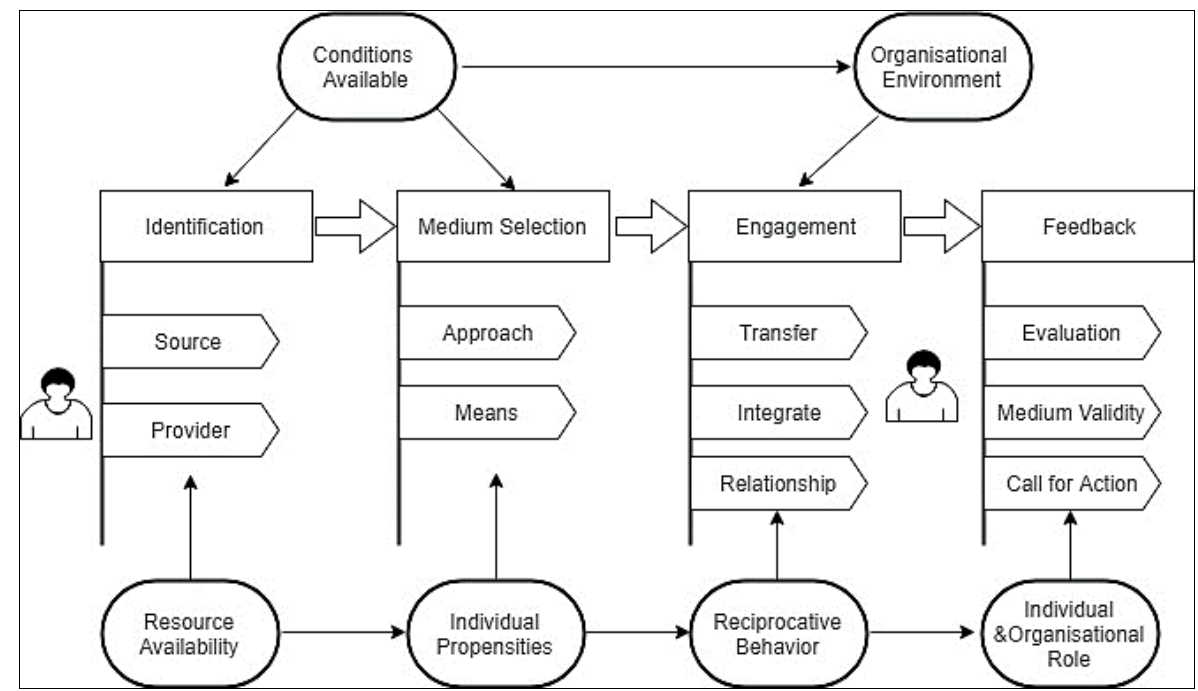

\subsection{Identification stage}

During the first stage of the KS process, the seeker explores the required knowledge and identifies the possible relevant sources that are available in the organisation. It is essential that the organisation supports all the necessary conditions for accessing knowledge and makes this knowledge available. For example, knowledge can be made explicit: the seeker is then able to solve problems using written documents, manuals, or work process charts. Alternatively, the organisation can identify resources i.e., a colleague, supervisor, or manager, that an individual can approach for their tacit knowledge. These resources then become knowledge providers because they hold the solution to the seeker's problem.

We observed that SMEs have numerous face-to-face interactions, an informal culture and easy-going approaches to sharing knowledge, as they do not have a strong hierarchical structure. Identifying a possible knowledge source is therefore usually easier than in larger structures. Often, supervisors claim that they create and provide all the necessary conditions to encourage employees to come to them for the knowledge they need. Some supervisors make it a point to mention repeatedly "please ask us questions to help you learn to do things right, rather than make mistakes...We are here to help you" (supervisor QCH-8). This helps employees approach supervisors effectively, as there is no fear ("when I need help, I just admit that I don't know and ask for my supervisor to connect me to a source where I can find help": trainee, PEI-2). However, when it comes to a colleague or other senior managers, employees must make sure they are aware of these individuals' expectations and take the initiative to develop a favourable relationship that is propitious to KS as, otherwise, they might fail to obtain the required knowledge. This is probably why employees tend to favour individuals who are close to them and whom they already know well as knowledge providers: "I feel content to seek help from the person who I know already or I would rather approach my immediate supervisor": Operation assistant, KOP-1; "It depends on whether I have a previous relationship with 
that person or not. If I know him already through other personal exchanges, then it's easy to obtain knowledge from him. If he is just a professional acquaintance, then my approach would definitely be friendly and soft and this process [of KS] will help build up the relation" (application developer, OFS-4).

In any case, the knowledge seeker has to identify the knowledge source: "when I want to finish the task, identifying the optimal source of knowledge is important, based on the type of knowledge we need. I mostly think that my supervisor is the source for most of the knowledge that I need for my job" (data analyst, IIS-3) and "We have resources identified to provide knowledge; since our work sometimes involves sensitiveness, even if we know what to do, we often cross check or consult our coworkers or manager" (application developer, OFS-4).

\subsection{Medium selection stage}

This stage is challenging and is decisive in terms of whether the provider engages in actual knowledge transfer. Once the seeker has identified the source of the needed tacit knowledge, this stage begins with an attempt to find an appropriate means or behavioural approach to obtain the knowledge. Now the question is "how do I approach her/him? How should I ask? What is the best way to obtain the knowledge that I need from her/him? Through face-to-face meeting? Through e-mails?" From our interviews, it was made evident that most employees seek supervisors or immediate co-workers' support through face to face interaction. Our data also indicated that this stage depends on the complexity of the knowledge needed and the issue in hand. The medium selection stage further depends on the individual characteristics of both seeker and provider. For instance, people have different needs, desires and goals, and they choose from various possible behaviours by analysing what type of behaviour is most likely to lead to the desired results (Krok, 2013). "It depends on our personal characteristics and our approach. Depending on the source, I adjust my behaviour. For example, my supervisor is my reporting boss, so I am more polite when I ask him. When I need knowledge from my co-workers, I adopt a friendly approach" (service engineer, OFS-4). Our data showed that the older the provider, the higher the respect the seeker has for him/her and the longer the provider's experience within the firm, the more polite the attitude adopted by the seeker: "I either communicate with humility, or approach with respect, I see which is best based on the personality, age and experience of the individual and my comfort level" (customer supervisor, QCH-8).

Research found that the main antecedents of KS include:

1 individual providers' characteristics (e.g., Judge and Bono, 2001)

2 interpersonal characteristics (e.g., Chowdhury, 2005; Mooradian et al., 2006).

This stage helps behavioural dynamics initiated by the seeker and the approach chosen is highlighted. The seeker uses certain means to approach the provider, before actually asking for the knowledge needed. This stage constitutes the start of relationship building where the seeker engages in conversation with the provider. Depending on the situation, the appropriate means selected could be, for example, mail, face to face communication, telephone, use of ICT to share knowledge (Ruggles, 1998; Ruikar et al., 2007; Olsson et al., 2008), or social exchange (Zigan et al., 2010). 
Here, recipients say that some providers have expectations as to how they wish to be approached. For example, for a training session on understanding the trouble-shooting skills of machinery equipment, the trainer is highly knowledgeable and has many years of experience with the machinery. Since he is more senior, this trainer might expect personal humility from the knowledge seeker rather than a standard professional approach. Others might deliver and give knowledge because they consider it their duty. However, the provider's willingness to share their knowledge appears to depend on the seeker's way of using the chosen medium. Means have a strong influence on the end results. For instance, some people willing to share their knowledge will expect others to reciprocate for mutual benefit and to achieve organisational goals (Lin, 2007; Adler and Kwon, 2002). According to Zhang and Jiang (2015), two important factors impact KS: the seeker's attitude and the relationship between seeker and provider. If the seeker demonstrates a learning attitude (modest, open-minded, humble) then the provider's willingness to share is inclined to increase: "When I don't know anything, I become like a student and show respect when asking my colleague or supervisor how to solve the problem" (office assistant, TE-5); "When I need a solution, I try to be humble when I ask, that way, I know the person will be keen to help me" (operation assistant, KOP-1) and "When seeking knowledge, I feel I should be soft and keep a low-profile in my approach" (estate assistant, NE-6). "If I must find a solution, I will be soft in my approach" (data analyst, IIS-3). Conversely, if the seeker's attitude shows hubris, arrogance and pretentiousness then the provider might be reluctant to share. We found that the best approach for the seeker to adopt depends on the individual propensities and specificities of both seeker and provider and also on the surrounding context

\subsection{Engagement stage}

During this stage, when the provider is within his/her comfort zone and is willing to share his/her knowledge, seeker and provider engage and knowledge starts transferring from provider to seeker. While engaging, the conversations and interactions also help create a shared experience (Dixon, 1997), build trust, strengthen the relationships between participants (Harkins, 1999) and are a prerequisite for effective KS (Szulanski, 1996). While interacting, the provider 'transfers' the necessary knowledge, which furthermore is well integrated by the seeker, thus we refer to this as knowledge integration. In dyadic actions, the knowledge receiver tries to absorb the knowledge and utilise it based on her/his requirements. The useful part of knowledge can then be integrated into the receiver's own knowledge.

From our observation and data, we find that there are many ways fora seeker and provider to engage: "Our knowledge sharing is based on interests that we share when we engage in more informal discussions, I have seen colleagues learn new things during these informal exchanges and we develop a strong bond" (estate assistant, NE-6) and "Our supervisors or our senior employees, engage well and offer us coffee or snacks in knowledge sharing sessions, they become very friendly and ensure that we learn everything. However, this also depends on how we have approached them" (marketing executive, AE-9). Hence, to some extent, the provider engages and participates willingly and fully because he knows that he has been approached in the 'right' way by his colleague.

In some instances, the seeker expects providers to be generous in sharing what they know. In turn, there are often expectations from the provider, which the seeker observes 
before engaging. Interviews revealed that for learning and the transfer of experience to happen, the knowledge provider must understand the seeker's needs and then provide the relevant knowledge. The receiver integrates the knowledge obtained and then starts to implement it.

From our data, we observed that this might be a slow process, depending on the provider's time, availability, mood and whether there is reciprocal behaviour. This stage holds good if there is reciprocal behaviour towards sharing knowledge: all actors need to align their interests in participating in the KS process (Tabrizi and Morgan, 2014). Therefore, the KS engagement stage further depends on the organisation environment and on how management motivates and facilitates the KS process. Some firms do not have technical facilities that people can use to communicate and share knowledge (ICT, for example). However, most KS seekers expect firms to provide a KS environment for them to be effective in learning and sharing: "In our company, our organisation provides a separate room or facility for such sharing to happen. In fact, we seek and fix time, depending on the supervisor or senior colleague's schedule and we engage in conversation. This helps us develop a strong relationship with our supervisors and colleagues" (estate assistant, TE-5). Our study revealed that the organisational environment plays a crucial role in the sharing of knowledge. For example, in some SMEs, colleagues engaged in KS activity on the working platform may create disturbance for other workers. Some participants mentioned that they tend to wait for lunch time or outside office hours to approach their colleagues or supervisor to avoid conflicts: "Our supervisors use lots of examples and repetitions to integrate what we want and they tell us that if we do not understand, we can ask them during lunch time or coffee break. Because they feel that if they don't give us what we want and the right amount, we might make mistakes" (purchase assistant, RE-7). This confirms Anand and Walsh's (2015) findings that SME employees are often happier to share knowledge in informal environments rather than in a formal office environment.

Once engagement has actually occurred, mutual trust develops between seeker and provider: "My co-workers help us out a lot, mostly the senior employees, they help train and make sure that we become expert. During this sharing process, I have seen my colleagues becoming closer and we develop a good friendship. Knowledge sharing has helped us develop trustful relationships with our colleagues" (assistant manager, QCH-8).

\subsection{Feedback stage}

This stage has not previously been highlighted nor studied in the literature, even though our data highlights it as essential in the KS process. During the feedback stage, the seeker primarily evaluates whether s/he obtained the desired knowledge that was sought, whether her/his approach was adequate and served her/his purpose ("My colleague's mood and behaviour were different compared to previous interactions. I do not know if his mood was bad or my approach was not good enough or perhaps someone said something negative about me, so he avoided answering": estate assistant, NE-6).

However, we found that in some instances, the seeker also thinks about the problems he faced while seeking knowledge: "I have seen my colleague behaving very secretively at times and, at other times, he was being sarcastic in front of others with hints about the way I asked him some things. Maybe he was expecting me to be more respectful or decent? It's difficult for me to say what the problem was" (customer relation executive, AE-9) and "My supervisor was rude to me on several occasions. It was difficult for me to 
understand why. However, my other colleagues told me it was because of my approach, which he did not like. Consequently, he was reluctant to share knowledge with me and when he had to do it, he was rude" (Purchase assistant, RE-7).

Perhaps seekers should systematically check whether a satisfactory result is achieved i.e., whether they in fact obtained the knowledge they needed. If they did not, they should perhaps identify the reasons why and what could have been improved during the KS process. For instance, they could evaluate whether their approach was suitable or whether they made a mistake, sometimes even after the start of the KS process. If their approach was perceived as offensive by the provider, then the KS process was probably impeded during the engagement stage. Thus, feedback is important to evaluate whether the medium used was suitable.

Benefits, experiences and lessons can be learned during the last stage of the KS process and organisations can call for actions to rectify possible issues and concerns encountered during this process. Organisations may face constraints internally or externally from the conditions in which KS operates. Some conditions create unstable environmental influences. To solve these issues and tackle this kind of situation, firms need to be able to adapt instantly and accurately by exploiting existing knowledge in order to enhance their competitive advantage. Hence, organisations have to rely on available knowledge that is being shared by members. However, our results tend to highlight that the seeker rarely tries to evaluate what he receives; rather, if the knowledge received is found to be wrong or inadequate, the seeker simply approaches others and, if the originally acquired knowledge must be rectified, s/he rarely suggests to the original provider that there was anything wrong.

Hence, nurturing this fourth stage and feedback loop in SMEs might improve and facilitate the KS process, make it more effective and also improve the quality of knowledge shared. Organisations could consider providing a platform for knowledge seekers and providers to evaluate concerns and issues related to the KS process, so it can be more effective.

\section{Discussion: theoretical implications and future research}

Our model differs from previous KS models found in the literature, which attempt to theorise the sharing process in different contexts (e.g., Hansen, 1999, Szulanski, 2000; Tabrizi and Morgan, 2014). Since our focus is on SMEs, in our model, the stages of the KS process are subdivided into several specific sub-stages to make KS clearer from the seeker and provider perspectives. The model proposed is a theoretical tool for understanding the sharing process of how knowledge seeking happens, and how knowledge is given and absorbed in SMEs. Our model expands the understanding of the various elements that may impact the KS process during any of the stages highlighted and described; it also extends existing models found in the literature (e.g., Hansen, 1999; Szulanski, 2000; Tabrizi and Morgan, 2014). Our study thus provides an improvisation strategy for managers to further strengthen their work process. More particularly it appears essential to consider the fourth stage and feedback loop for a SME to become more of a learning organisation.

In the SMEs investigated, our approach was to study the dyadic nature of sharing mechanisms. Hence, we focused mostly on tacit KS between seeker and provider. Our findings suggest that understanding managers' behaviour towards influencing employees 
to seek and share knowledge is also an important element to consider in the KS process. Although for SMEs tacit KS is at the core of their operations, their efforts towards KS become least effective when their employees do not engage in KS behaviours. Given the loss to SMEs implied by not sharing knowledge, SMEs should invest more effort in facilitating KS among employees at the workplace. For example, providing training on interpersonal relationship skills among employees, creating a culture of citizenship behaviour, encouraging employees to connect for the purpose of helping and assisting. As our research shows, seeker and provider may adopt different approaches: firms should probably pay more attention to increasing their citizenship behaviour.

Most models found in the literature investigate knowledge creation and knowledge acquisition, from group and organisational perspectives, for example, Nonaka's (1994) work involves large organisations and highlights knowledge creation from the individual level to the organisational level; our results appear to be in line with the Nonaka's 'externalisation' (tacit to tacit) part of sharing knowledge among employees in SMEs. Wong and Radcliffe (2000), suggest that tacit knowledge in SMEs is difficult to turn into explicit knowledge and tacit sharing happens mostly during socialisation and informally, which is in line with some of our own findings (Egbu et al., 2005). SMEs have different structures and they develop different patterns of behaviour especially in adapting to the environment (Hashim, 2007). Most SMEs, both in manufacturing and service industries, cannot afford to have or adopt knowledge management systems (Jagannathan, 2014), this is why SMEs rely on employees' tacit KS activity for success (Ngah and Jusoff, 2009).

The qualitative data we obtained from interviews raised very few concerns about employees not sharing with each other, as employees were expected to share their knowledge. However, employees do not always do so, and tacit knowledge is volatile and may be lost if not shared. From our data, it was clear that in SMEs, KS occurs mostly through face-to-face exchanges (Egbu et al., 2005; Bock and Kim, 2002) and informal social interactions (Anand and Walsh, 2015). Knowledge providers mostly expect a humble attitude from seekers: this is most probably because India as a country and more specifically Bangalore as a region in the South of India, have mixed socio emotional values, grounded in national cultural values. Cultural values of course do shape and play a role in people's behaviour, more particularly during the medium selection and engagement stages.

\section{Limitation}

Our study has several limitations, which should be addressed in future research. As we wished to have an in-depth insight, we chose to use qualitative data, hence limiting de facto the number of participants. Further, our results were obtained in the context of Indian SMEs specifically located in a southern region of India. Culture, norms, and policies have been highlighted as important predictors of KS behaviour (Wang and Noe, 2010). Further research would be useful to investigate the role of culture in relation to rewards (monetary and non-monetary) and conflicts as well as, more broadly, whether the proposed model holds true for other regions of India / other parts of the world and in larger firms. Furthermore, more emphasis is needed on the type of knowledge that is effectively shared. 


\section{Conclusions}

This study integrates empirical data collected in India and relevant key concepts from the literature to understand and model the KS process in SMEs. Our results highlight the importance of the organisational context (e.g., climate, environment, culture) and individuals' approach (e.g., humility, politeness and respect) as elements with high impact on the KS process. We examined the various stages and components of the KS process and their inter-relationships to draw implications for the sharing process. The proposed model could help organisations and individuals better understand factors influencing KS and provide valuable insight on how to choose appropriate means and approaches to make KS processes more effective. In a dyadic perspective, we found that four stages (identification, medium selection, engagement and feedback) appear essential in the KS process. We also found that firms could profitably focus on the detrimental effects of employees not sharing knowledge and on facilitating the KS process with a view to maintaining and/or developing their competitive advantage.

\section{References}

Adler, P.S. and Kwon, S-W. (2002) 'Social capital: prospects for a new concept', Academy of Management Review, Vol. 27, No. 1, pp.17-40.

Alavi, M. and Leidner, D.E. (2001) 'Review: knowledge management and knowledge management systems: conceptual foundations and research issues', MIS Quarterly, Vol. 25, No. 1, pp.107-36.

Ali, T. and Murali, R. (2009) 'Knowledge management obstacles in Malaysia: an exploratory study. Public sector ICT', Management Review, Vol. 3, No. 1, pp.15-20.

Anand A. and Walsh I. (2015) 'Empirical analysis of factors influencing knowledge sharing facilities and barriers in Indian SMEs - a comparative case study', Proceeding of the 16th European Conference on Knowledge Management, Italy.

Andolsek, D.M. (2011) 'Knowledge hoarding or sharing', International Conference on Management Knowledge and Learning, pp.167-176.

Anitha, C. (2006) Determinants of Knowledge Sharing Behaviour: Developing and Testing an Integrated Theoretical Model, $\mathrm{PhD}$ dissertation, The University of Texas, Arlington.

Barney, J. (1991) 'Firms resources and sustained competitive advantage', Journal of Management, Vol. 17, No. 1, pp.99-120.

Bartol, K. and Srivastava, A. (2002) 'Encouraging knowledge sharing: the role of organizational reward systems', Journal of Leadership \& Organizational Studies, Vol. 9, No. 1, pp.64-76.

Berends, H. (2005) 'Exploring knowledge sharing: moves, problem solving and justification', Knowledge Management Research and Practices, Vol. 3, No. 2, pp.97-105.

Bock, G.W., Zmud R.W., Kim, Y.G. and Lee J.N. (2005) 'Behavioural intention formation in knowledge sharing: examining the roles of extrinsic motivators, social psychological forces, and organizational climate', MIS Quarterly, Vol. 29, No. 1, pp.87-111.

Bock, G-W. and Kim, Y-G. (2002) 'Breaking the myths of rewards: an exploratory study of attitudes about knowledge sharing', Information Resources Management Journal, Vol. 15, No. 2, pp.14-21.

Brčić, Ž.J. and Mihelič, K.K. (2015) 'Knowledge sharing between different generations of employees: an example from Slovenia', Economic research-Ekonomska istraživanja, Vol. 28, No. 1, pp.853-867.

Cabrera, A. and Cabrera, E. (2002) 'Knowledge sharing dilemmas', Organizational Studies, Vol. 23, No. 5, pp.687-710. 
Chowdhury, S. (2005) 'The role of affect- and cognition-based trust in complex knowledge sharing', Journal of Managerial Issues, Vol. 17, No. 3, pp.310-326.

Cohen, S. and Kaimenakis, N. (2007) 'Intellectual capital and corporate performance in knowledge-intensive SMEs', The Learning Organization, Vol. 14, No. 3, pp.241-262.

Davenport, T.H. and Prusak, L. (1998) Working Knowledge: How Organizations Manage What they Know, Harvard Business School Press, Boston, MA.

Desouza, K.C. and Awazu, Y. (2006) 'Knowledge management at SMEs: five peculiarities', Journal of Knowledge Management, Vol. 10, No. 1, pp.32-43.

Dhamija, S. and Arora, R.K. (2017) 'Initial and after-market performance of SME IPOs in India', Global Business Review, Vol. 18, No. 6, pp.1536-1551.

Dixon, N. (1997) 'The hallways of learning', Organizational Dynamics, Vol. 25, No. 4, pp.23-34.

Durst, S. and Edvardsson, I.R. (2012) 'Knowledge management in SMEs: a literature review', Journal of Knowledge Management, Vol. 16, No. 6, pp.879-903, doi:10.1108/ 13673271211276173.

Egbu, C.O., Hari, S. and Renukappa, S.H. (2005) 'Knowledge management for sustainable competitiveness in small and medium surveying practices', Structural Survey, Vol. 23, No. 1, pp.7-21.

Eze U.C, Goh, G.G.G., Goh, C.Y. and Tan, T.L. (2013) 'Perspectives of SMEs on knowledge sharing', VINE, Vol. 43, No. 2, pp.210-236.

Fernie, S., Green, S.D., Weller, S.J. and Newcombe, R. (2003) 'Knowledge sharing: context, confusion and controversy', International Journal of Project Management, Vol. 21, No. 3, pp.177-187.

Fink, K. and Ploder, C. (2009) 'Balanced system for knowledge process management in SMEs', Journal of Enterprise Information Management, Vol. 22, Nos. 1/2, pp.36-50.

Gibbert, M. and Krause, H. (2002) 'Practice exchange in a best practice marketplace', in Davenport, T.H. and Probst, G.J.B. (Eds.): Knowledge Management Case Book: Best Practices, pp.68-84, Publicis MCD, Berlin.

Glaser B.G. (1978) Theoretical Sensitivity, Sociology Press, Mill Valley. CA.

Glaser, B.G., Strauss, A.L. and Strutzel, E. (1968) 'The discovery of grounded theory; strategies for qualitative research', Nursing Research, Vol. 17, No. 4, p.364.

Hansen, M.T. (1999) 'The search-transfer problem: the role of weak ties in sharing knowledge across organization subunits', Administrative Science Quarterly, Vol. 44, No. 1, pp.82-111.

Harkins, P. (1999) Powerful Conversations: How High Impact Leaders, Communicate, McGraw Hill, New York.

Hashim, M.K. (2007) SMEs in Malaysia: A Brief Handbook, August Publishing Sdn. Bhd, Kuala Lumpur.

Ibrahim, S. and Heng, L.H. (2015) 'The roles of learning in stimulating knowledge sharing at SMEs', Procedia-Social and Behavioral Sciences, Vol. 172, pp.230-237.

Ipe, M. (2003) 'Knowledge sharing in organizations: a conceptual framework', Human Resource Development Review, Vol. 2, No. 4, pp.337-359.

Ismail, W.K., Nor, K.M. and Marjani, T. (2009) The role of knowledge sharing practice in enhancing project success', Interdisciplinary Journal of Contemporary Research in Business, Vol. 1, No. 7, pp.34-52.

Jagannathan, R. (2014) The Indian SME Survey Analysing Indian SME Perceptions Around Union Budget 2014-15, July, pp.1-20, Greyhound Knowledge Group, India.

Jain, M.K. and Gandhi, S.K. (2016) 'Defining Indian SMEs: a critical analysis', International Journal of Arts, Humanities and Management Studies, Vol. 2, No. 6, pp.12-25.

Judge, T.A. and Bono, J.E. (2001) 'Relationship of core self-evaluations traits - self-esteem, generalized self-efficacy, locus of control, and emotional stability - with job satisfaction and job performance: a meta-analysis', Journal of Applied Psychology, Vol. 86, No. 1, pp.80-92. 
KPMG (2015) The New Wave Indian MSME [online] https:/assets.kpmg.com/content/dam/ $\mathrm{kpmg} / \mathrm{pdf} / 2016 / 03 /$ The-new-wave-Indian-MSME.pdf (accessed January 2018).

Krok, E. (2013) 'Willingness to share knowledge compared with selected social psychology theories', Contemporary Economics, Vol. 7, No. 1, pp.101-109.

Levy, M.L., Lobbecke, C. and Powell, P. (2003) SMEs, co-opetition and knowledge sharing: the role of information systems', European Journal of Information Systems, Vol. 12, No. 1, pp. $3-17$

Liang, T.P., Liu, C.C. and Wu, C.H. (2008) 'Can social exchange theory explain individual knowledge-sharing behavior? A meta-analysis', ICIS 2008 Proceedings, p.171.

Lin, C-C. (2005) 'A cross-level examination of organizational citizenship behavior: an analysis using hierarchical linear modelling (HLM)', Journal of Management, Vol. 22, pp.503-524.

Lin, H.F. (2007) 'Knowledge sharing and firm innovation capability: an empirical study', International Journal of Manpower, Vol. 28, Nos. 3/4, pp.315-332.

Massaro, M., Handley, K., Bagnoli, C. and Dumay, J. (2016) 'Knowledge management in small and medium enterprises: a structured literature review', Journal of Knowledge Management, Vol. 20, No. 2, pp.258-291.

Michailova, S. and Hutchings, K. (2004) 'National cultural influences on knowledge sharing: a comparison of China and Russia', Journal of Management Studies, Vol. 43, No. 3, pp.383-405.

Mooradian, T., Renzl, B. and Matzler, K. (2006) 'Who trusts? Personality, trust and knowledge sharing', Management Learning, Vol. 37, No. 4, pp.523-540.

Naif-Marouf, L. (2007) 'Social networks and knowledge sharing in organizations: a case study', Journal of Knowledge Management, Vol. 11, No. 6, pp.110-125.

Ngah, R. and Jusoff, K. (2009) 'Tacit KS and SMEs' organizational performance', International Journal of Economics and Finance, Vol. 1, No. 1, pp.216-220.

Nonaka, I. (1994) 'A dynamic theory of organizational knowledge creation', Organization Science, Vol. 5, No. 1, pp.14-37.

Nonaka, I. and Takeuchi, H. (1995) The Knowledge-Creating Company. How Japanese Create the Dynamics of Innovation, Oxford University Press, New York.

Olsson, E., Wismen, M. and Carlsson, S. (2008) 'Permanent and temporary work practices: knowledge integration and the meaning of boundary activities', Knowledge Management Research \& Practice, Vol. 6, No. 4, pp.260-273.

Paulin, D. and Suneson, K. (2012) 'Knowledge transfer, knowledge sharing and knowledge barriers - three blurry terms in KM', The Electronic Journal of Knowledge Management, Vol. 10, No. 1, pp.81-91.

Pillania, R. (2008) 'Strategic issues in knowledge management in small and medium enterprises', Knowledge Management Research \& Practice, Vol. 6, No. 4, pp.334-338.

Reige, A. (2005) 'Three-dozen knowledge sharing barriers managers must consider', Journal of Knowledge Management, Vol. 9, No. 3, pp.18-35.

Ruggles, R. (1998) 'The state of the notion: knowledge management in practice', California Management Review, Vol. 40, No. 3, pp.80-89.

Ruikar, K., Anumba, C.J. and Egbu, C. (2007) 'Integrated use of technologies and techniques for construction knowledge management', Knowledge Management Research \& Practice, Vol. 5, No. 4, pp.297-311.

Shariq, S.Z. (1999) 'How does knowledge transform as it is transferred? Speculations on the possibility of a cognitive theory of knowledge capes', Journal of Knowledge Management, Vol. 3, No. 4, pp.243-251.

Singh, M.D., Shankar, R., Narain, R. and Kumar, A. (2006) 'Survey of knowledge management practices in Indian manufacturing industries', Journal of Knowledge Management, Vol. 10, No. 6, pp.110-128. 
Srivastava, A., Bartol, K.M. and Locke, E.A. (2006) 'Empowering leadership in management teams: effects on knowledge sharing, efficacy, and performance', Academy of Management Journal, Vol. 49, No. 6, pp.1239-1251.

Sutton, J. and Austin, Z. (2015) 'Qualitative research: data collection, analysis, and management', The Canadian Journal of Hospital Pharmacy, Vol. 68, No. 3, pp.226-231.

Szulanski, G. (1996) 'Exploring internal stickiness: impediments to the transfer of best practice within the firm', Strategic Management Journal, Vol. 17, No. S2, pp.27-43.

Szulanski, G. (2000) 'The process of knowledge transfer: a diachronic analysis of stickiness', Organisational Behaviour Human Decision Processes, Vol. 82, No. 1, pp.9-27.

Tabrizi, N.M. and Morgan, S. (2014) 'Models for describing knowledge sharing practices in the healthcare industry: example of experience knowledge sharing', International Journal of Management and Applied Research, Vol. 1, No. 2, pp.48-67.

Van den Hooff, B. and De Ridder, J. A. (2004) 'Knowledge sharing in context: the influence of organisational commitment, communication climate and CMC use on knowledge sharing', Journal of Knowledge Management, Vol. 8, No. 6, pp.117-130.

Wang, S. and Noe, R. (2010) 'KS: a review and directions for future research', Human Resource Management Review, Vol. 20, No. 2, pp.115-131, Elsevier Inc.

Wong, W.L.P. and Radcliffe, D.F. (2000) 'The tacit nature of design knowledge', Technology Analysis and Strategic Management, Vol. 12, No. 4, pp.493-512.

Wrenn, B., Stevens, R.E. and Loudon, D.L. (2007) Marketing Research, 2nd ed., Routledge Publishers, UK.

Zhang, X. and Jiang, J.Y. (2015) 'With whom shall I share my knowledge? A recipient perspective of knowledge sharing', Journal of Knowledge Management, Vol. 19, No. 2, pp.277-295.

Zigan, K., Macfarlane, F. and Desombre, T. (2010) 'Knowledge management in secondary care: a case study', Knowledge and Process Management, Vol. 17, No. 3, p.118.

\section{Appendix}

Table A1 Classification of SMEs in India

\begin{tabular}{lcc}
\hline Type of enterprise & $\begin{array}{c}\text { Manufacturing enterprises } \\
\text { investment in plant and machinery }\end{array}$ & $\begin{array}{c}\text { Service sector enterprises } \\
\text { investment in plant and }\end{array}$ \\
\hline Micro enterprises & Up to INR 50 lakh & Up to INR 20 lakh \\
Small enterprises & $\begin{array}{c}\text { More than INR 50 lakh INR but } \\
\text { does not exceed INR10 crore } \\
\text { More than INR 10 crore but does } \\
\text { not exceed INR 30 crore }\end{array}$ & $\begin{array}{c}\text { More than INR 20 lakh but does } \\
\text { not exceed INR 5 crore } \\
\text { Medium enterprises than 5 crore rupees but does } \\
\text { not exceed INR 15 core }\end{array}$ \\
\hline
\end{tabular}

Notes: INR is the currency of India (Indian National Rupees).

A lakh is a unit in the Indian numbering system equal to 100,000 .

A crore is equal to 100 lakh Indian Rupees. 